\title{
Lucanian Vegetation Database
}

\author{
Leonardo Rosati, Giovanna Potenza \& Simonetta Fascetti
}

\begin{abstract}
Electronic databases of vegetation plots are considered useful tools for ecological analysis, monitoring and conservation purposes and have been established in many different European countries. In Italy we highlight a general lackof large database regarding flora and vegetation issues. In the Laboratory of Environmental and Applied Botany Laboratory of the Basilicata University, in 2010 we started to assemble a regional databases of vegetation plots using the TURBOVEG software, which is widely used to store vegetation data in an electronic format, to classify and analyse large phytosociological tables and other ecological data (e.g life forms, Ellenberg indicator values etc.). The Basilicata regional database includes published and unpublished data regarding the administrative Region and conterminous areas. We considered for inclusion in the database phytosociological relevés or any other vegetation plots containing records of species composition (of at least vascular plants) and an estimate of species cover. We extended the standard structure of the database by defining extra fields to fit particular needs, such as including the precision of the data location (i.e. a crucial issue for environmental monitoring). A reference check-list of the taxa was set up mostly following Conti et al. (2005) including several largely adopted synonymous to facilitate the correct input of relevé data. The ecological database are linked to the vascular species list such as Ellenberg indicator values, life forms or chorotypes. The Lucanian Vegetation Database (GIVD ID EU-IT003) includes approximately 1,700 relevé and, contains useful information to test several ecological hypotheses and for wide-scale vegetation classification. Furthermore it facilitates the data flow between the national and local databases and makes it easier to use vegetation-plot data for conservation issues such as biodiversity and habitat monitoring and for land use/cover changes evaluation. Related to this project we started to update the check-list of syntaxa, the list of publications regarding flora and vegetation, the herbarium database and we plan to assemble a provisional syntaxonomical scheme for the region.
\end{abstract}

Keywords: environmental monitoring; phytosociology; vegetation classification.

\section{Lucanian Vegetation Database}

Scope: In the Laboratory of Environmental and Applied Botany of the Basilicata University, we started in the 2010 to assemble a regional databases of vegetation plots regarding the Basilicata region (Southern Italy) to analyse and classify large phytosociological tables and other ecological data (e.g. life forms, Ellenberg indicator values...).

Status: ongoing capture

Period: $1972-2011$

Database manager(s): Leonardo Rosati (leonardo.rosati@unibas.it)

Owner: Leonardo Rosati, Simonetta Fascetti (private)

Web address: http://www.unibas.it/utenti/rosati/laboratorio_file/page0009.htm

Availability: according to a specific agreement

Online upload: no

Online search: no

Database format(s): TURBOVEG

Export format(s): TURBOVEG

Publication: [NA]

Plot type(s): normal plots

Non-overlapping plots: 1,810

Plot-size range: $1-800 \mathrm{~m}^{2}$

Total plot observations: 1,810

Estimate of existing plots: 2,300

Completeness: $79 \%$

Countries: IT: $100.0 \%$

Forest: [NA] — Non-forest: [NA]

Guilds: all vascular plants: $100 \%$

Environmental data: altitude: $80 \%$; slope aspect: $80 \%$; slope inclination: $80 \%$; soil depth: $80 \%$

Performance measure(s): cover: $100 \%$

Geographic localisation: GPS coordinates (precision $25 \mathrm{~m}$ or less): 10\%; point coordinates less precise than GPS, up to $1 \mathrm{~km}$ : $40 \%$; political units or only on a coarser scale $(>10 \mathrm{~km}): 50 \%$

Sampling periods: [NA]

Information as of 2012-07-12; further details and future updates available from http://www.givd.info/ID/EU-IT-003

Leonardo Rosati* (leonardo.rosati@unibas.it), Giovanna Potenza (Potenza@unibas.it), Simonetta Fascetti

(simonetta.fascetti@unibas.it)

Department of Biology, Università della Basilicata, Via dell'Ateneo Lucano 10, 85100 Potenza, ITALY

*Corresponding author 